\title{
The Impact of Uncertainties in Ice Sheet Dynamics on Sea-Level Allowances at Tide Gauge Locations
}

\author{
Aimée B. A. Slangen ${ }^{1,2}, *$, Roderik S. W. van de Wal ${ }^{2}$, Thomas J. Reerink ${ }^{2}$, Renske C. de Winter ${ }^{3}$, \\ John R. Hunter ${ }^{4}$, Philip L. Woodworth ${ }^{5}$ and Tamsin Edwards 6 \\ 1 Royal Netherlands Institute for Sea Research (NIOZ), Department of Estuarine and Delta Systems (EDS), \\ Utrecht University, Korringaweg 7, Yerseke 4401 NT, The Netherlands \\ 2 Institute for Marine and Atmospheric research Utrecht (IMAU), Princetonplein 5, Utrecht 3584 CC, \\ The Netherlands; r.s.w.vandewal@uu.nl (R.S.W.v.d.W.); tjreerink@gmail.com (T.J.R.) \\ 3 Department of Physical Geography, Utrecht University, Heidelberglaan 2, Utrecht 3584 CS, The Netherlands; \\ r.c.dewinter@uu.nl \\ 4 Antarctic Climate \& Ecosystems Cooperative Research Centre, 20 Castray Esplanade, Hobart TAS 7000, \\ Australia; jrh@johnroberthunter.org \\ 5 National Oceanography Centre, 6 Brownlow Street, Liverpool L3 5DA, UK; plw@noc.ac.uk \\ 6 School of Environment, Earth \& Ecosystem Sciences, Faculty of Science, Technology, Engineering \& \\ Mathematics, The Open University, Milton Keynes MK7 6AA, UK; tamsin.edwards@open.ac.uk \\ * Correspondence: aimee.slangen@gmail.com; Tel.: +31-0-113-577-300
}

Academic Editors: Thomas Wahl, Jan Even Øie Nilsen, Ivan Haigh and Sally Brown Received: 10 March 2017; Accepted: 16 May 2017; Published: 23 May 2017

\begin{abstract}
Sea level is projected to rise in the coming centuries as a result of a changing climate. One of the major uncertainties is the projected contribution of the ice sheets in Greenland and Antarctica to sea-level rise (SLR). Here, we study the impact of different shapes of uncertainty distributions of the ice sheets on so-called sea-level allowances. An allowance indicates the height a coastal structure needs to be elevated to keep the same frequency and likelihood of sea-level extremes under a projected amount of mean SLR. Allowances are always larger than the projected SLR. Their magnitude depends on several factors, such as projection uncertainty and the typical variability of the extreme events at a location. Our results show that allowances increase significantly for ice sheet dynamics' uncertainty distributions that are more skewed (more than twice, compared to Gaussian uncertainty distributions), due to the increased probability of a much larger ice sheet contribution to SLR. The allowances are largest in regions where a relatively small observed variability in the extremes is paired with relatively large magnitude and/or large uncertainty in the projected SLR, typically around the equator. Under the RCP8.5 (Representative Concentration Pathway) projections of SLR, the likelihood of extremes increases more than a factor $10^{4}$ at more than $50-87 \%$ of the tide gauges.
\end{abstract}

Keywords: sea-level rise; allowances; sea-level extremes

\section{Introduction}

Sea level is projected to rise in the coming century and beyond as a result of a warming climate, with major contributions from warming of the ocean water and increasing land ice mass loss [1]. To protect against or mitigate the effects of sea-level rise (SLR) in highly populated coastal zones, it is important to understand the processes causing SLR, and to reduce the uncertainties for each of the projected contributions. Sea-level rise here is relative sea-level change, i.e., the difference as measured by tide gauges attached to the Earth's surface. Presently, one of the main uncertainties in SLR is the contribution of the Antarctic and Greenland ice sheets [2,3]. Particularly the timing and magnitude of 
dynamical changes associated with the ice sheets (e.g., marine ice sheet instability) are still uncertain. This is therefore an active area of research.

In the Fifth Assessment Report (AR5) of the Intergovernmental Panel on Climate Change (IPCC), the projected ice dynamical contribution to SLR was based on observations and a range of scenarios from models ([1], Table 13.5). Around the same time, Bamber and Aspinall [4] presented an estimate based on expert judgement, which had a strongly skewed uncertainty distribution rather than the symmetric distribution presented in IPCC. With the same data but a different way to process the expert opinions, De Vries and Van de Wal [5] presented an estimate with a lower high-end estimate than Bamber and Aspinall [4], though still a strongly skewed uncertainty distribution. Although expert elicitations document the level of consensus on a certain topic, they are sensitive to, for instance, the level of expertise of the interviewees and the way experts are selected. Therefore, process-based estimates are generally a preferable method. Until recently, process-based estimates were only available for specific parts of the ice sheets (e.g., Pine Island Glacier [6] or Thwaites Glacier [7]). However, Ritz et al. [8] recently presented an estimate for the Antarctic ice dynamical contribution to SLR in the 21st century using a process-based approach. They too found a non-normal distribution of the uncertainties, though less skewed than the De Vries and Van de Wal [5] distribution.

In this study, we will compare and contrast three different types of uncertainty distributions for the mass loss contribution to SLR due to ice dynamics $[1,5,8]$. We will specifically look at the effect on sea-level allowances rather than focusing on the sea-level projections. A sea-level allowance indicates the height a coastal structure needs to be elevated to maintain the same frequency and likelihood of extreme sea-level events under future SLR $[9,10]$. An allowance gives more information than just a $90 \%$ or $95 \%$ confidence level of projected mean SLR because it also accounts for the local variability in the sea-level extremes. An important assumption for the allowances in general is that the variability in the extremes does not change under the influence of climate change. For the 20th century, this is a reasonable assumption, as Menéndez and Woodworth [11] found that the historical change in extremes is mostly due to changes in mean sea level rather than changes in the storminess contributions to the extremes. For the 21st century, model projections of changes in the wave climate and storm surges are subject to large uncertainties, and it is therefore difficult to say if the assumption will hold in the future [1].

We use the regional relative sea-level projections of Slangen et al. [12], which describe the change of the ocean surface relative to the ocean floor. The projections follow the high-end RCP8.5 (Representative Concentration Pathway [13]) climate change scenario based on CMIP5 model output (5th phase of the Climate Model Intercomparison Project [14]). While these projections assume a normal (Gaussian) uncertainty distribution, more recent publications have incorporated skewed ice sheet dynamics distributions into their projections to provide a more complete uncertainty distribution (e.g., [15-18]) which can be used for risk-assessment and policy purposes. We follow this line and combine the Slangen et al. [12] sea-level projections with three different ice sheet dynamics scenarios (Section 2.1) using the framework of De Winter et al. [18]. Whereas De Winter et al. [18] discussed the impact and sensitivity of the high-end regional sea-level projections to different ice sheet uncertainty distributions, here we focus on the effect of the shape of the skewed ice sheet uncertainty distributions on the projected allowances. De Winter et al. [18] showed that the 90th, 95th and 97.5th percentiles of regional SLR projections are highly sensitive to the uncertainty distribution of ice sheet dynamics. In contrast to De Winter et al. [18], all the ice sheet dynamics scenarios will be shifted to the same median (as described in Section 2.1) to focus on the effects of the different shapes rather than differences in their magnitude. Previously, regional allowances were mainly computed using normal (Gaussian) uncertainty distributions for the projected SLR [10]. Buchanan et al. [19] used full probability distributions in combination with allowances to compute an "Average Annual Design-Life Level" for the United States coastline. Here, we present allowances for skewed uncertainty distributions for tide gauge stations across the world and compare the different shapes of the distributions (Section 2.3). 
There are various ways to express sea-level extreme events statistically, depending on the application and the quality of the available data. Methods such as fitting Generalised Extreme Value distributions (of which the Gumbel distribution is a special case) to annual maxima in water levels and fitting Generalised Pareto distributions to peaks over a threshold [20] are often used to represent the statistics of extreme water levels. There is no consensus as to a universal best approach [21], and the method chosen depends on the purpose of the analysis and the data availability and quality. Here, we use a Gumbel parameterisation, which will allow us to compute the allowances following Hunter [9] and Hunter et al. [10]. We use the GESLA-2 tide gauge dataset (Global Extreme Sea Level Analysis Version 2 [22,23], Section 2.2), which significantly increases the number of locations with respect to previous studies of allowances $[9,10]$. Finally, we show the increase in the frequency of sea level extremes under the RCP8.5 scenario if the allowances are not applied (Section 3.3).

\section{Data and Methodology}

\subsection{Uncertainty Distributions of Sea-Level Change}

We use the regional sea-level projections for the RCP8.5 scenario based on CMIP5 model output as presented in Slangen et al. [12], for the period 2010-2100. These projections are similar to the results presented in IPCC AR5 [1] and include the contributions of steric/dynamic change, glacier and ice sheet mass change, groundwater extraction and Glacial Isostatic Adjustment. The global mean projected change for 2010-2100 is $0.72 \pm 0.28 \mathrm{~m}$, of which the Antarctic dynamics mass loss contribution is $0.08 \pm 0.06 \mathrm{~m}$ and the Greenland dynamics mass loss contribution $0.05 \pm 0.06 \mathrm{~m}$. All uncertainty distributions in Slangen et al. [12] are assumed to be normal, with means and standard deviations as provided in their Table 1.

The two dynamical ice sheet contributions will be removed from the total projections of Slangen et al. [12], and replaced by three different scenarios for the ice sheet dynamically-driven mass loss. For clarity, this means that the ice sheet surface mass balance (SMB) contribution to SLR remains unaltered with respect to Slangen et al. [12]. The three scenarios used are:

(1) The IPCC scenario (Figure 1, green, from Church et al. [1]). We use the cumulative ice sheet dynamical contributions for the Antarctic Ice Sheet (AIS) and Greenland Ice Sheet (GRIS) as presented in IPCC AR5 Table 13.5 (0.05 $\pm 0.03 \mathrm{~m}$ for Greenland, $0.07 \pm 0.08$ for Antarctica), assuming a normal distribution. As Church et al. [1] present the change for 1986-2005 to 2081-2100, we correct the values linearly to estimate the change for 2010 to 2100 . The Antarctic contribution is split into 11\% for the East Antarctic Ice Sheet (EAIS) and 89\% for the West Antarctic Ice Sheet (WAIS), which is the split for the year 2010 as presented in the IMBIE project (Ice sheet Mass Balance Inter-comparison Exercise, [24]).

(2) The VW15 scenario (Figure 1, blue) is from De Vries and Van de Wal [5]. We use the skewed uncertainty distribution of rates of SLR in 2100 for WAIS, EAIS and GRIS contributions, based on expert elicitation estimates. VW15 presented a reanalysis of the data in Bamber and Aspinall [4], which more rigorously accounts for the lack of consensus in the expert estimates. To convert mm/year in 2100 into cumulative SLR for 2010-2100, we assume a rate of change in 2010 of $0.6 \mathrm{~mm} /$ year for WAIS, $0.0 \mathrm{~mm} /$ year for EAIS and $0.3 \mathrm{~mm} /$ year for GRIS following VW15 and Bamber and Aspinall [4], and assume a linear change in the rate for the period 2010-2100.

(3) The R15 scenario for the Antarctic dynamical ice sheet contribution (Figure 1, black) is from Ritz et al. [8]. This is an observation and model-based estimate of the ice dynamical mass loss for 2010-2100. The shape of the Antarctic distributions differs slightly from the original R15 study due to the use of a narrower bandwidth (less smoothing) in the kernel density estimation. For Greenland dynamics, this scenario is the same as the IPCC scenario, as R15 did not calculate the Greenland contribution.

All the ice dynamics scenarios are shifted to match the median values of the IPCC scenario (Figure 1, dashed lines), in order to make sure that the differences in the allowances are only due to changes in the shape of the distribution rather than the magnitude. We use the median (i.e., the point 
where the cumulative density function is 0.5 ) for this shift, rather than the mean, as the median is less sensitive to extremely large values in the non-normal distributions. Although the published VW15 estimates are for SMB and ice sheet dynamics combined, we here assume that the skewed shape of the distribution is primarily a result of the uncertainty in the dynamical processes and correct for the differences in magnitude by the aforementioned shift in the median.

The regional SLR for each of the ice sheet dynamics contributions is computed by multiplying each contribution as presented in Figure 1 (Greenland, East Antarctica, West Antarctica) with its respective sea-level "fingerprint" ratio (e.g., [25]). These fingerprints are computed with a gravitationally consistent sea-level model. The resulting projected ice dynamical contribution to the relative regional SLR was shown in Slangen et al. [12] in their Figure 1e. Typically, sea level falls near the sources of ice mass loss, and rises above average in the far field. The individual fingerprint ratios of each ice sheet may be scaled with the global mean SLR contribution of each ice sheet if the location of the mass change remains the same as the location used to compute the fingerprint. This assumption is most significant in proximity to the ice sheet, where gravitational gradients decrease relatively sharply from the centres of mass loss.
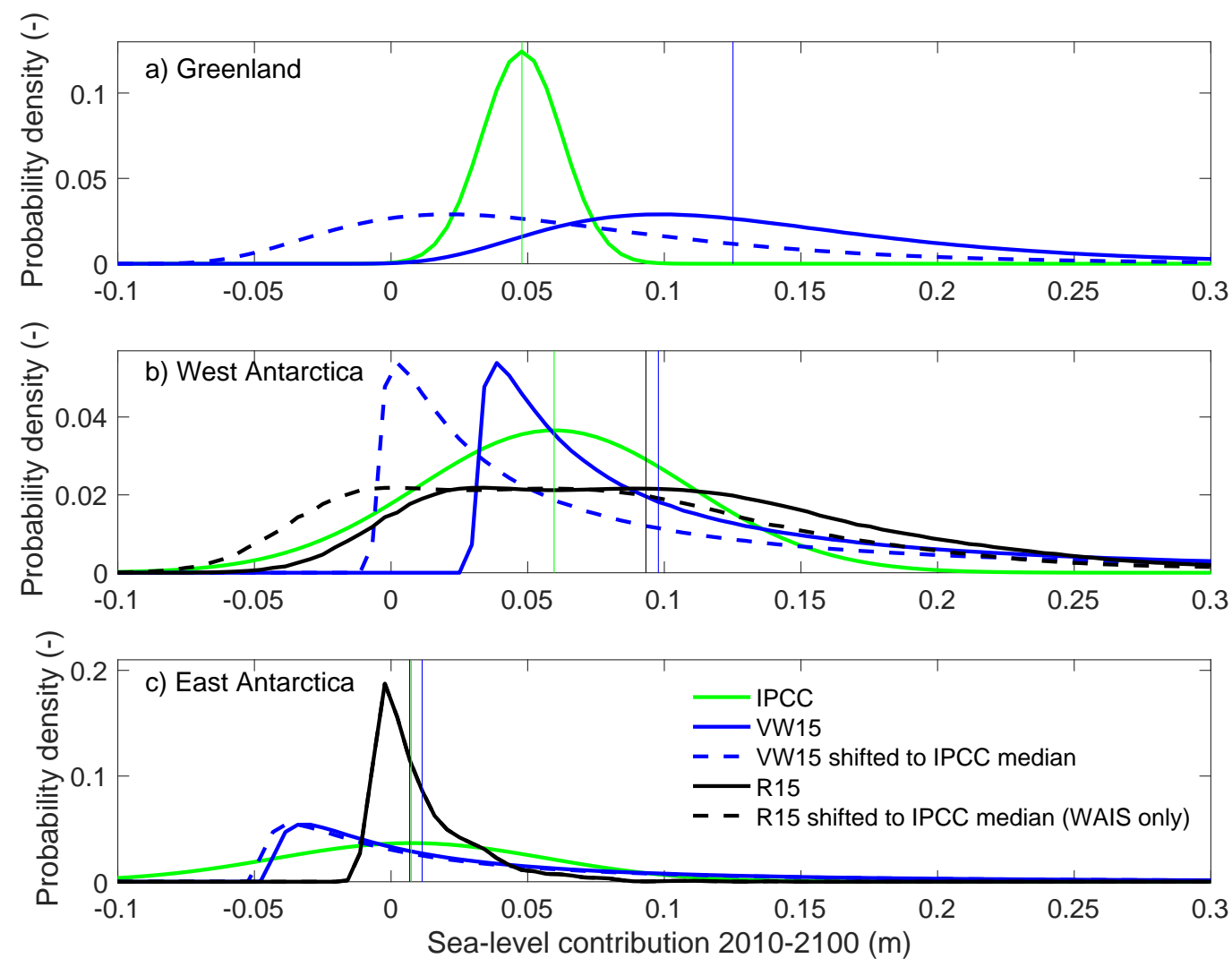

Figure 1. The three scenarios for ice sheet dynamics contributions to sea-level rise used in this study, for (a) Greenland, (b) West Antarctica and (c) East Antarctica (cumulative m sea-level change between 2010-2100). Original uncertainty distributions in solid lines, medians in vertical lines, shifted uncertainty distributions (where all medians match the IPCC medians) in dashed lines.

We use the SEAWISE model [18] to combine the skewed SLR distributions for Greenland, West-Antarctica and East-Antarctica one by one with the projected non-ice sheet dynamics SLR from Slangen et al. [12] (for which a normal distribution is assumed) at each tide gauge location (Appendix, Figure A1). SEAWISE first scales the ice dynamic uncertainty distributions with the individual fingerprints to obtain the ice sheet uncertainty distribution at each location. Then, SEAWISE combines multiple SLR distributions, e.g., for West-Antarctica and Greenland (these can be normal 
or skewed). The model can combine independent distributions or assign a correlation coefficient to assume a dependency between distributions. Here, all distributions are assumed to be independent. Details of the SEAWISE methodology are presented in the Appendix and in De Winter et al. [18].

\subsection{The Statistics of Sea-Level Extremes}

In addition to the regional sea-level projections, we require location-specific information on the statistics of sea-level extremes resulting from tides, storm surges and other (high-frequency) sea-level variability. For this, we use Gumbel scale parameters. The Gumbel scale parameter for a certain location can be derived from historical records of high-frequency sea-level measurements (see Figure 2 for four examples). Here, we use data from the GESLA-2 database (Global Extreme Sea Level Analysis Version 2 [22,23]), which contains high-frequency records (at least hourly) from 1300 tide gauge stations as of February 2016. Gumbel distributions were fitted to the annual maxima (expressed relative to the linear trend in mean sea level over the record) of each of the 658 tide gauges, using the Matlab ${ }^{\circledR}$ evfit (Mathworks, Natick, MA, USA) function, as described in Hunter et al. [26]. In a comparison of the Gumbel scale parameters obtained from the evfit method to the ismev method as used in Hunter [9] (both methods are extensively described in Hunter et al. [26]), we found that the results are very similar to the extent required for the present analysis and we therefore use the values from the Matlab ${ }^{\circledR}$ evfit method only. We select all tide gauge records that contain at least 20 years of data and where each year with data is more than $75 \%$ complete (Figure 3), which yields a data set of 658 records. Following Hunter et al. [26], we reject four stations that show significant non-Gumbel behaviour, and also leave out two Hudson Bay tide gauges (Canada) as we do not have sea-level projections available there. This leaves 652 records, of which 448 records have $\geq 30$ years of data available, 319 records $\geq 40$ years, 164 records $\geq 50$ years and 94 records $\geq 60$ years.
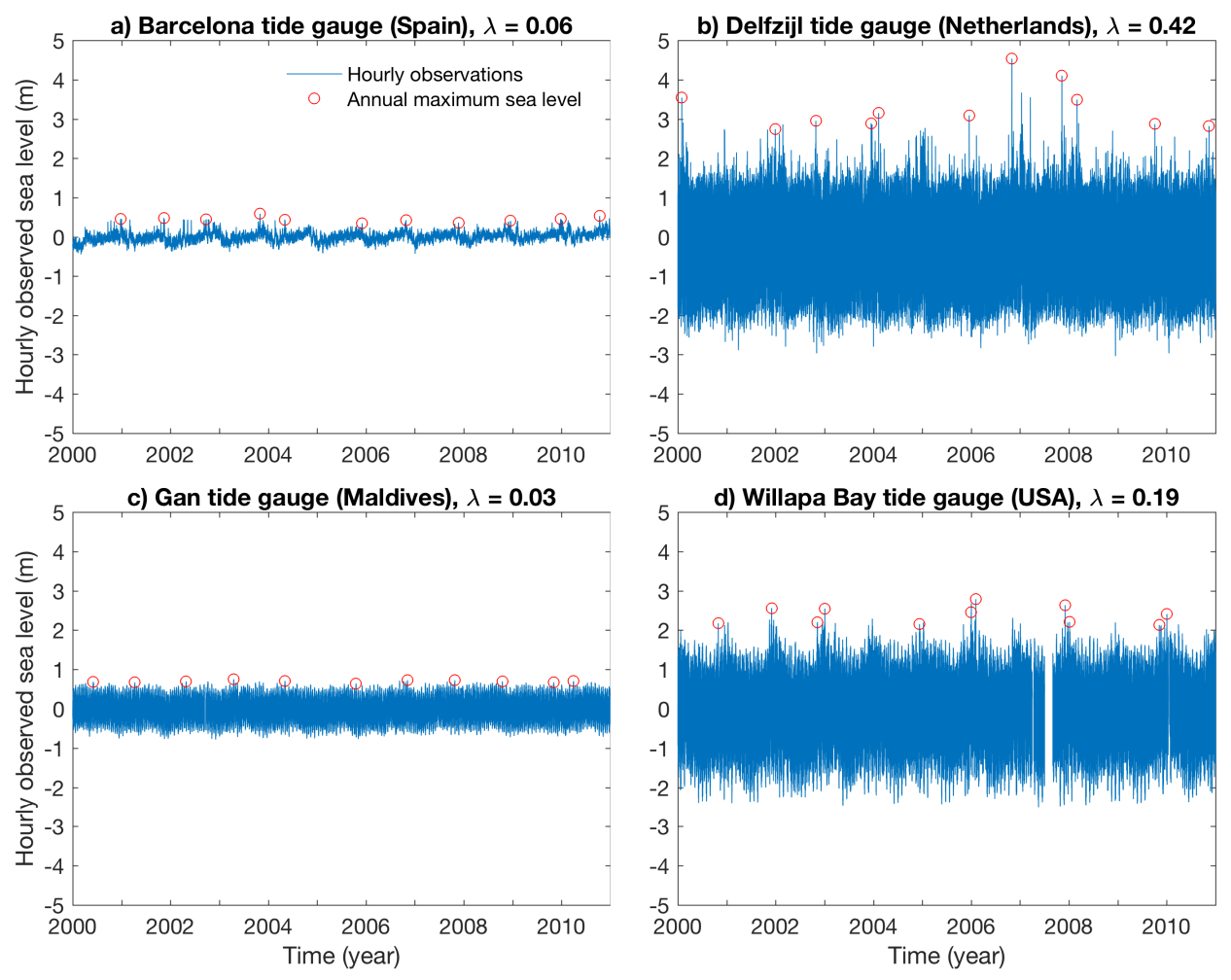

Figure 2. Four examples of tide gauge records: (a) Barcelona, (b) Delfzijl, (c) Gan, (d) Willapa Bay. Hourly data (in blue) and their annual maximum values (red) for 2000-2010 (m), where the mean of each time series has been removed. $\lambda=$ the Gumbel scale parameter $(\mathrm{m})$. Locations are indicated in Figure $5 \mathrm{a}$ by their first letter. 
The Gumbel scale parameter describes the variability of the extremes; i.e., a smaller parameter means that the variability in the extremes is small (e.g., Figure 2a,c) - this does not necessarily mean that the average magnitudes of the extremes are small. A larger scale parameter indicates larger variability in the extremes (e.g., Figure 2b,d). Sea-level extremes can be a combination of high tide and extreme storm surge, but also a medium tide and an extreme surge, or a high tide and a medium surge. Other factors such as interannual or seasonal variability can have significant effects as well: Barcelona (Figure 2a), for instance, has a strong seasonal cycle, leading to a more regular occurrence of the annual maximum than for instance in Delfzijl (Figure 2b). For a detailed discussion of contributing factors to extreme sea levels, we refer the reader to Merrifield et al. [27].

Historically, there have been more tide gauge stations in the Northern Hemisphere, resulting in a larger number of estimates of Gumbel scale parameters in the Northern Hemisphere than in the Southern Hemisphere. The Gumbel scale parameters are typically in the range of tenths of meters $(0.12 \pm 0.06 \mathrm{~m}$, mean $\pm 1 \sigma)$. Values are generally lower around the equator, increasing towards the mid-latitudes (specifically in the Northern Hemisphere), with the highest values between $40^{\circ}$ and $70^{\circ} \mathrm{N}$ (Figure 3), where both the tidal range and the storm surge activity tend to be larger [27]. For instance, Gumbel scale parameters are high at the Dutch coast (e.g., Figure 2b, Delfzijl tide gauge), due to a large tidal range and a large variability in storm surge heights. This is the result of the geometry of the semi-enclosed and relatively shallow North Sea basin, resulting in the development of larger storm surges under north western storm wind conditions, while the storm surge levels are considerably lower for other wind directions (e.g., [28]). This in contrast to the Barcelona tide gauge (Figure 2a), which has a much smaller tidal range since it is located in the Mediterranean and experiences less extreme storm surge heights.

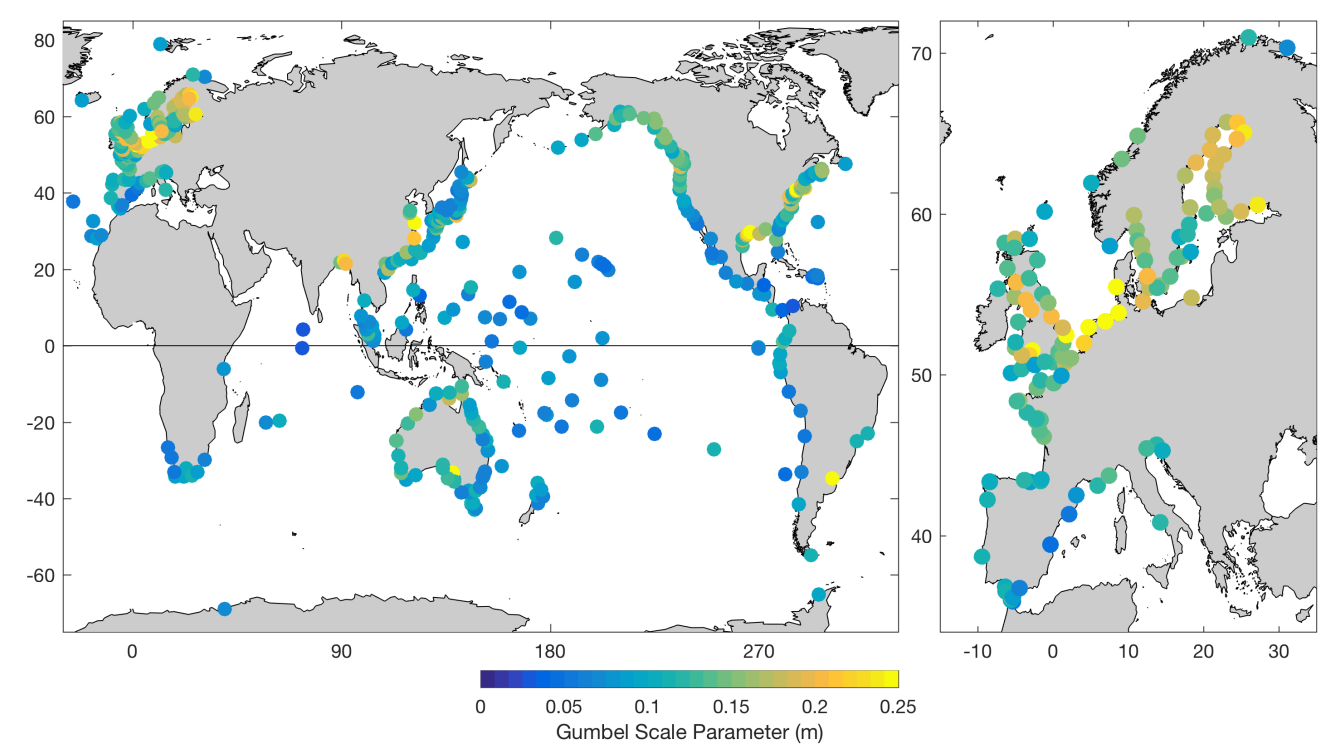

Figure 3. (left) Gumbel scale parameters (m) at 652 tide gauge stations and (right) a zoom on the European region.

\subsection{Allowances Methodology}

We assume a projected sea-level rise by an amount $z^{\prime}$, where $z^{\prime}$ has an uncertainty distribution function $P\left(z^{\prime}\right)$. If a coastal structure is raised by an allowance $a$ to preserve the frequency of extreme (flooding) events in the future, $a$ is given by

$$
a=\lambda \ln \left(\int_{-\infty}^{\infty} P\left(z^{\prime}\right) \exp \left(\frac{z^{\prime}}{\lambda}\right) d z^{\prime}\right)
$$


where $\lambda$ is the scale parameter of the Gumbel distribution (Section 2.2), which describes the sea level extreme events and which is assumed to remain unchanged under sea-level rise. For the full derivation of the allowance, the reader is referred to Hunter [9] and Hunter et al. [10]. Note that, in these earlier papers, $z^{\prime}$ was defined relative to a projected mean sea level, whereas here we use $z^{\prime}$ as the total projected sea level to simplify the equations.

For a normal distribution, the allowance can be reduced to a simple analytical form:

$$
a_{\text {normal }}=\mu+\frac{\sigma^{2}}{2 \lambda}
$$

(Equation viii in Supplementary Material of Hunter [9]), where $\mu$ is the mean SLR and $\sigma$ the standard deviation of SLR when $P\left(z^{\prime}\right)$ follows a normal distribution.

However, Equation (2) is only valid for simple normal distributions of SLR. As we want to test different types of (non-normal) uncertainty distributions, the approach needs to be modified. We first redefine the skewed distributions of the projected SLR (from Section 2.1) in such a way that they can be used in the allowance computation. This is done by using a nonlinear fitting procedure (Powell's method, Press et al. [29]), which fits up to four normal distributions (see Figure 4 for an example) to optimally represent the (skewed) sea-level distribution. Then, the equation for the allowances only needs to be modified such that the allowance represents this group of normal distributions rather than just one normal distribution.

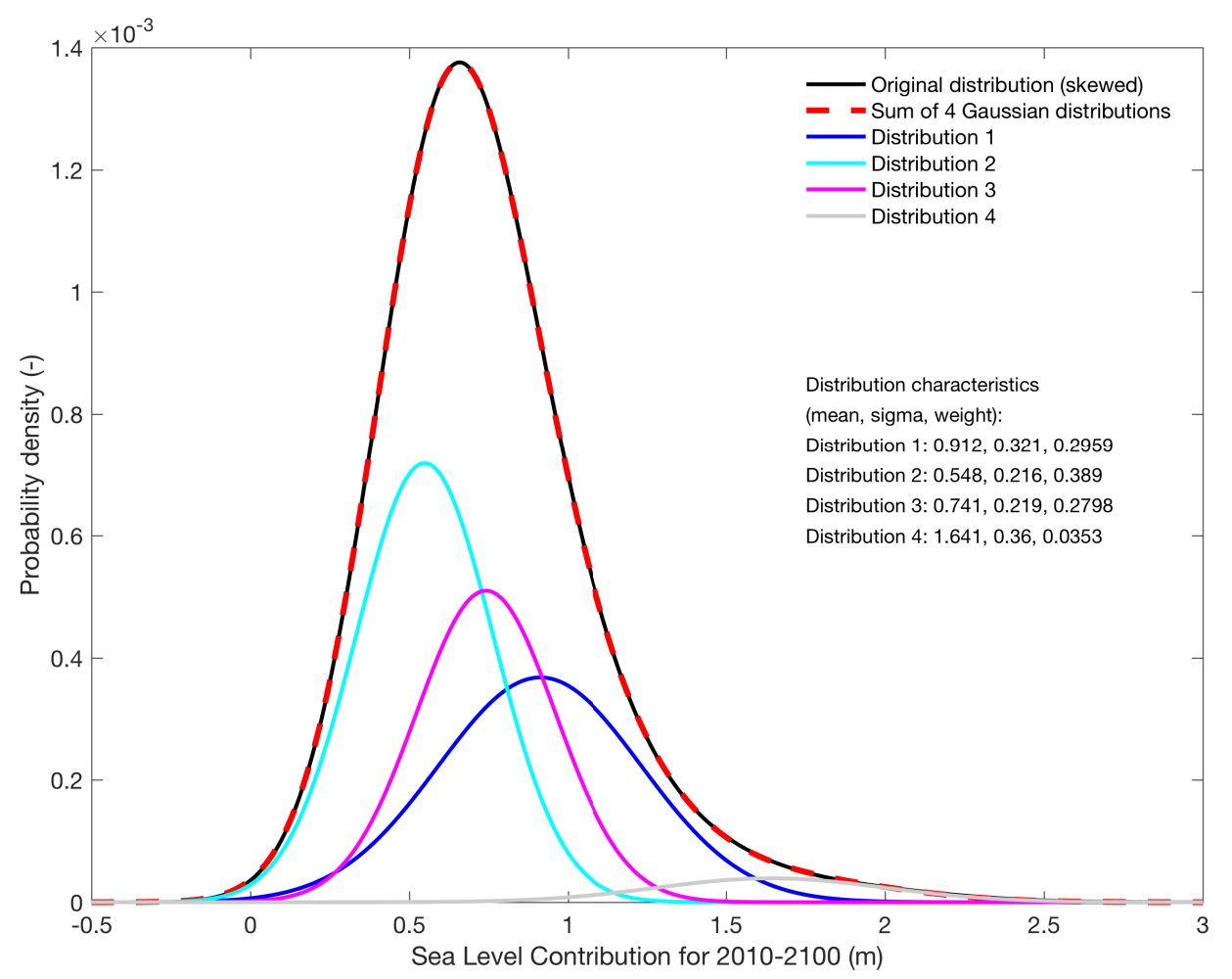

Figure 4. Example of a skewed sea-level uncertainty distribution (black), broken down into a set of four normal distributions (blue), which together describe the original distribution best (red dash).

We start from the description of a single normal distribution with a zero mean and standard deviation $\sigma$, where $P\left(z^{\prime}\right)$ is expressed as:

$$
P\left(z^{\prime}\right)=\frac{1}{\sigma \sqrt{2 \pi}} \exp \left(-\frac{\left(z^{\prime}\right)^{2}}{2 \sigma^{2}}\right)
$$


(Eq. ii from Supplementary Material of Hunter [9]). Then, the distribution $P\left(z^{\prime}\right)$ is modified such that it represents a group of normal distributions rather than one normal distribution:

$$
P\left(z^{\prime}\right)=\frac{1}{\sqrt{2 \pi}} \sum_{i=1}^{n} \frac{w_{i}}{\sigma_{i}} \exp \left(-\frac{\left(z^{\prime}-\mu_{i}\right)^{2}}{2 \sigma_{i}^{2}}\right)
$$

where each distribution $i$ in the group of normals has a weight $w_{i}$, a standard deviation $\sigma_{i}$, and is centered on $\mu_{i}$, such that $P\left(z^{\prime}\right)$ is described by a group of $n$ normal distributions. The sum of all weights $w$ equals 1, where individual weights may be negative. Now, Equation (4) is inserted in Equation (1):

$$
\int_{-\infty}^{\infty} P\left(z^{\prime}\right) \exp \left(\frac{z^{\prime}}{\lambda}\right) d z^{\prime}=\sum_{i=1}^{n} w_{i} \exp \left(\frac{\mu_{i}}{\lambda}+\frac{\sigma_{i}^{2}}{2 \lambda^{2}}\right)
$$

This results in the following definition of the allowance for a group of normal distributions:

$$
a_{\text {skewed }}=\lambda \ln \left(\sum_{i=1}^{n} w_{i} \exp \left(\frac{\mu_{i}}{\lambda}+\frac{\sigma_{i}^{2}}{2 \lambda^{2}}\right)\right)
$$

This equation will be used to compute allowances for non-normal distributions in the remainder of the paper. For one normal distribution $(n=1)$ with weight 1 , Equation (6) reduces again to Equation (2).

\section{Results}

\subsection{Sea-Level Projections for 2010-2100}

Sea-level projections are computed for each grid point of the RCP8.5 projections of Slangen et al. [12] in conjunction with the regional patterns of the three scenarios for ice sheet dynamics (Section 2.1), which leads to three sea-level projection scenarios (Figure 5). In the three scenarios, the median values (i.e., the point where the cumulative density function reaches 0.5 ) of the uncertainty distributions of WAIS, EAIS and GRIS are set to match the IPCC median values (Figure 1, dashed lines) in order to study only the effect of the change in the shape of the uncertainty distributions, rather than the shifts in magnitude. This is a different approach compared to the work presented in De Winter et al. [18], who did not shift the medians, as the purpose of that study was to look at the sensitivity of the high-end percentiles of regional sea-level projections to different ice sheet scenarios, considering both the shape and the magnitude of the distributions.

As a result of the differences in the shape of the ice sheet dynamics distributions, the final median SLR is not exactly the same for the three scenarios, even though the medians of the individual contributions are the same. Therefore, the VW15 scenario has a higher median (over the global ocean area) of $0.81 \mathrm{~m}$ compared to $0.71 \mathrm{~m}$ for IPCC and $0.73 \mathrm{~m}$ for R15 (Figure 5, left column). The maps show low or negative SLR around the glaciers and ice sheets. As a result of projected changes in the ocean heat content and circulation, there is a dipolar band associated with a shift in the Antarctic Circumpolar Current stretching south of South Africa and Australia [30] and generally higher values in a wide band around the equator in the Indian and Pacific Oceans.

The 95th percentile figures of the sea-level projections (Figure 5, right column) show significantly larger values for the VW15 scenario compared to the other two scenarios, reaching projected SLR over $1.75 \mathrm{~m}$. The global mean 95th percentile of the VW15 scenario is $1.56 \mathrm{~m}$, which is higher than the other two scenarios (1.16 m IPCC and $1.18 \mathrm{~m} \mathrm{R15).} \mathrm{This} \mathrm{is} \mathrm{a} \mathrm{result} \mathrm{of} \mathrm{the} \mathrm{skewness} \mathrm{of} \mathrm{the} \mathrm{VW15}$ dynamical ice sheet uncertainty distribution, which has a heavier tail that leads to much higher values for the 95th percentile of all three dynamical ice sheet contributions in the VW15 scenario (Figure 1). Although the R15 scenario has a higher 95th percentile contribution for the West-Antarctic ice dynamics (+0.12 m compared to IPCC) and a slightly longer tail to higher values, the shape of the distribution is less skewed than that of the VW15 scenario. The R15 East Antarctic 95th percentile contribution 
is smaller (-0.04 $\mathrm{m}$ compared to IPCC) due to the distribution being much sharper than the IPCC distribution. Combined, the 95th percentile total SLR of R15 is only marginally larger than that of $\operatorname{IPCC}(+0.02 \mathrm{~m})$.

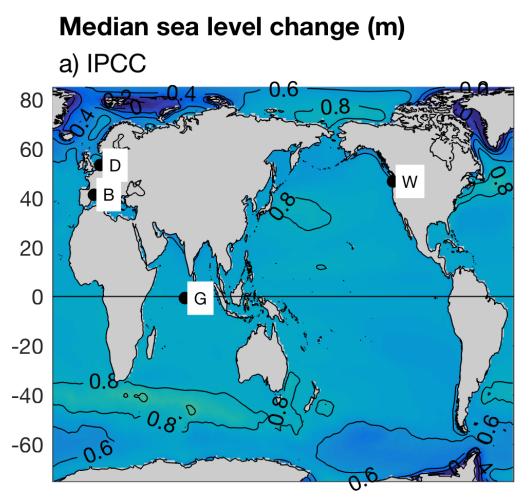

\section{5th percentile sea level change (m)}

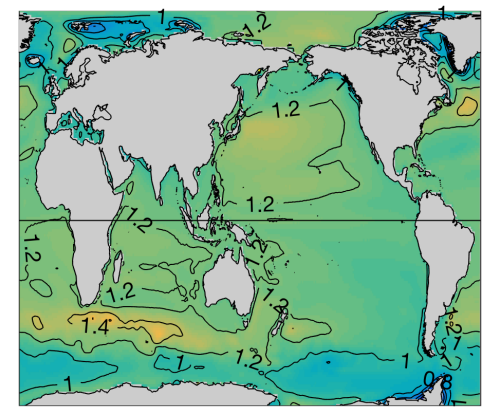

b) VW15 (Greenland and Antarctica dynamics shifted to match IPCC median)
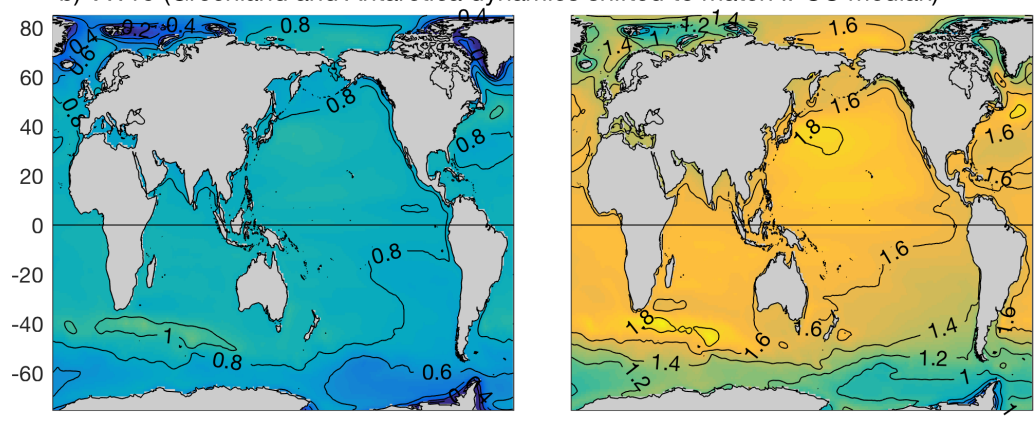

C) R15 (Antarctica dynamics shifted to match IPCC median, Greenland dynamics = IPCC)

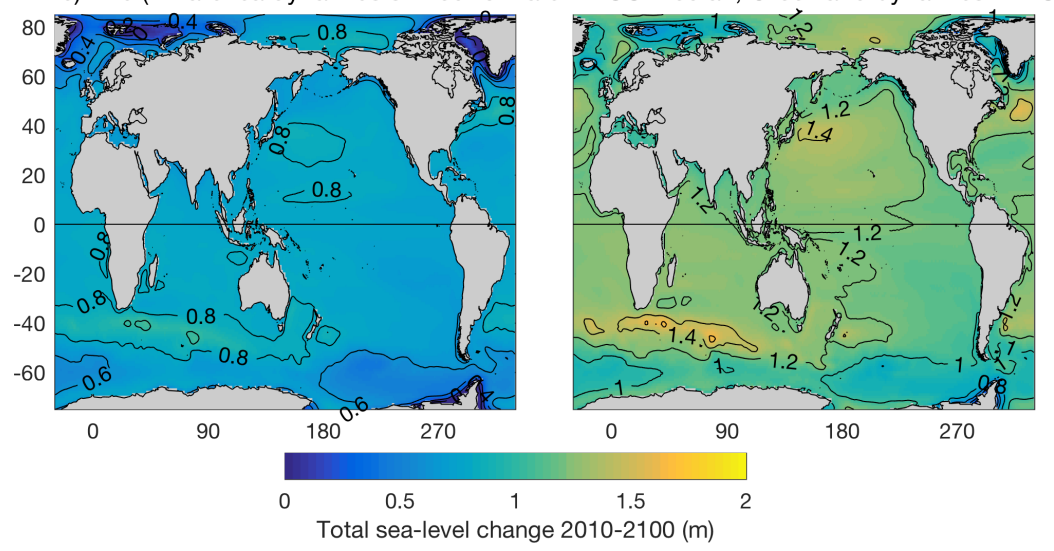

Figure 5. Projected cumulative sea-level change (m) for 2010-2100; median (left column) and 95th percentile (right column). All projections have the same median for the projected individual dynamical ice sheet contributions to SLR but a different shape of the uncertainty distribution. (a) IPCC; (b) VW15; (c) R15. The locations of the tide gauges in Figure 2 are indicated in (a) by their first letter.

\subsection{Allowances for Different Uncertainty Distributions}

From the sea-level projections and the Gumbel scale parameters, we compute sea-level allowances for the year 2100 (with respect to 2010) as outlined in Section 2.3. The allowances can only be computed at tide gauge locations, where Gumbel scale parameters are available. The projected SLR for each location is taken from the regional sea-level maps using a nearest neighbour approach. In some regions with multiple tide gauge stations, this means that the same sea-level projection grid point will be used for different stations. 
Similar to the 95th percentile sea-level projections (Figure 5), the allowances show a distinct effect from the skewed distribution of the VW15 scenario, and less so from the more mildly skewed R15 distribution (Figure 6, left column). On average, the VW15 allowances are more than twice as large as the allowances in the other two scenarios (2.19 m vs. 1.01 (IPCC) and 1.03 (R15) m). For the normal and close to normal distributions, it appears that the allowance is slightly less than the 95th percentile SLR at the tide gauge locations (which is $1.08 \mathrm{~m}$ for IPCC and $1.12 \mathrm{~m}$ for R15). For the skewed VW15 distribution, the allowance is much larger than the 95th percentile SLR at the tide gauges $(1.50 \mathrm{~m})$, due to the heavy upper tails of the uncertainty distributions of the dynamical ice sheet contributions.
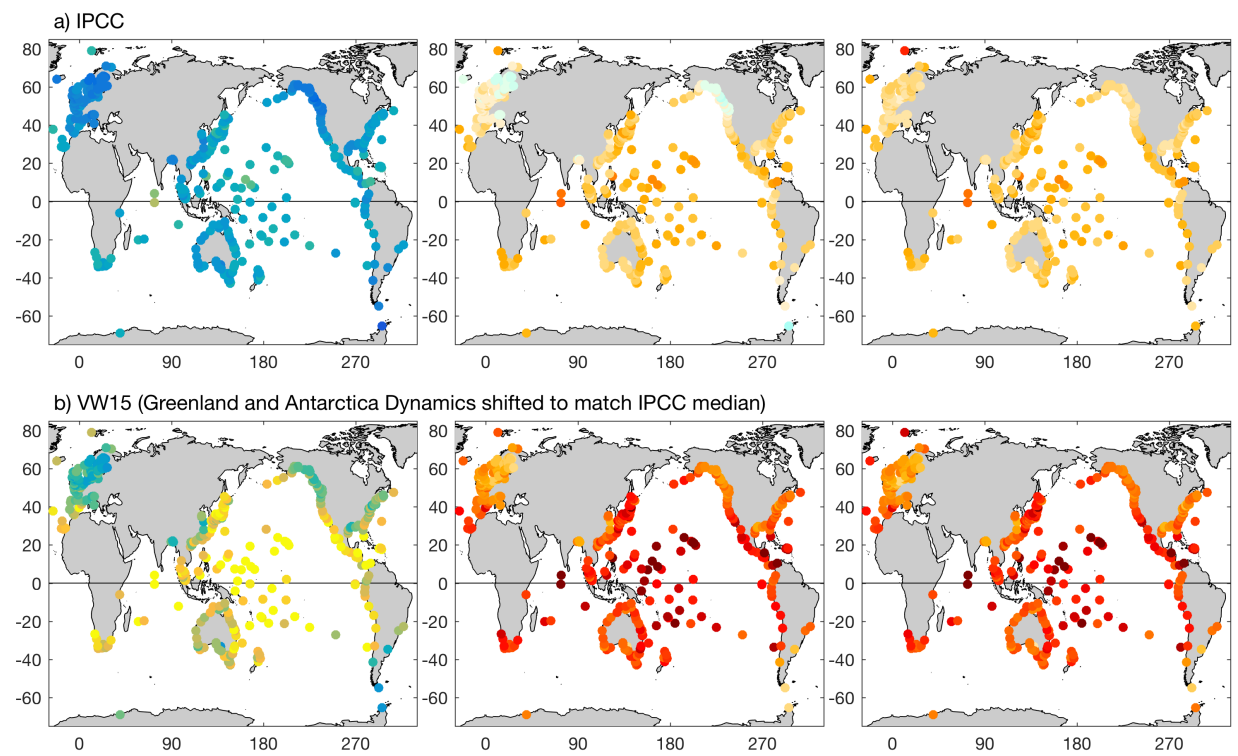

c) R15 (Antarctica dynamics shifted to match IPCC median, Greenland Dynamics = IPCC)
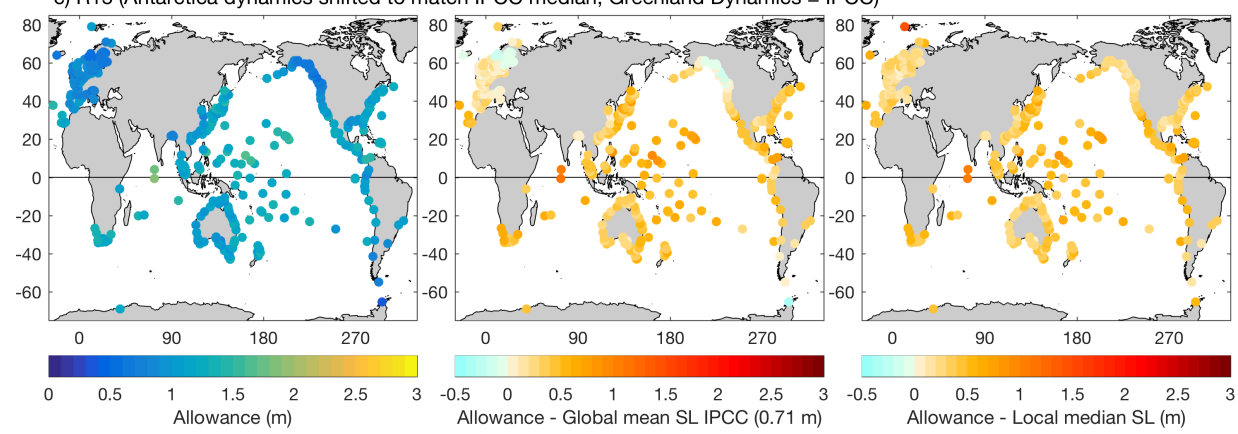

Figure 6. Allowances (m) for 2100 (left column), Allowances minus global mean SLR (middle column, $\mathrm{m}$ ) and Allowances minus local SLR (right column, m), using 2010-2100 sea-level change projections, all projections have the same median for the projected dynamical ice sheet contributions to SLR but a different shape of the uncertainty distribution. (a) IPCC; (b) VW15; (c) R15.

When we compare the allowance to the global mean SLR (Figure 6, middle column) and to the local projected SLR (Figure 6, right column), this shows that an allowance is more than a simple addition of the change in the mean sea level: it accounts for the local distribution of extremes through the Gumbel scale parameter as well. In some regions, the projected local SLR is less than the global mean change in the IPCC and R15 scenarios, for instance in the Baltic Sea and the northwest of the United States. Although the allowance may be less than the global mean SLR in some places, it is always larger than the local SLR (compare middle to right columns, Figure 6). The largest differences between the projected SLR (global and regional) and the allowances are in and along the Central Pacific ocean basin, where Gumbel scale parameters (Figure 3) tend to be lower (indicating smaller variability in the 
extremes) and projected SLR and its uncertainty tend to be higher (due to large distance from ice mass loss sources and large steric/dynamic changes).

A focus on Europe (Figure 7) shows that the allowances in this region fall between 0.5 and $1 \mathrm{~m}$ for the IPCC and R15 scenarios, while the allowances are larger for the VW15 scenario, being at least $1 \mathrm{~m}$ and as much as $2.5 \mathrm{~m}$. The allowances pattern generally is opposite to the Gumbel scale parameter (Figure 3): regions with higher Gumbel scale parameters tend to have lower allowances and vice versa. Due to Glacial Isostatic Adjustment (ongoing response of the solid Earth following ice sheet unloading after the Last Glacial Maximum [31]), the projected SLR is lower in the Baltic, leading to lower allowances in all three scenarios. Around the Mediterranean basin, projected SLR is substantial and the present sea-level variability is relatively small (small Gumbel scale parameters), which leads to the highest allowances in Europe (Figure 2a).

There is no immediately obvious relation between the Gumbel scale parameter and the projected mean SLR, apart from a tendency for locations with a smaller Gumbel scale parameter $(<0.1 \mathrm{~m})$ to be in locations with an average to above-average SLR projection, for all three scenarios (Figure 8). However, if the allowance is included (colours in Figure 8), a pattern emerges in the allowance that results from the combination of the projections and the scale parameters. It shows that tide gauges with smaller Gumbel scale parameters and larger projected SLR (uncertainties) require larger allowances to maintain the same likelihood of flooding (following Equation (6)).

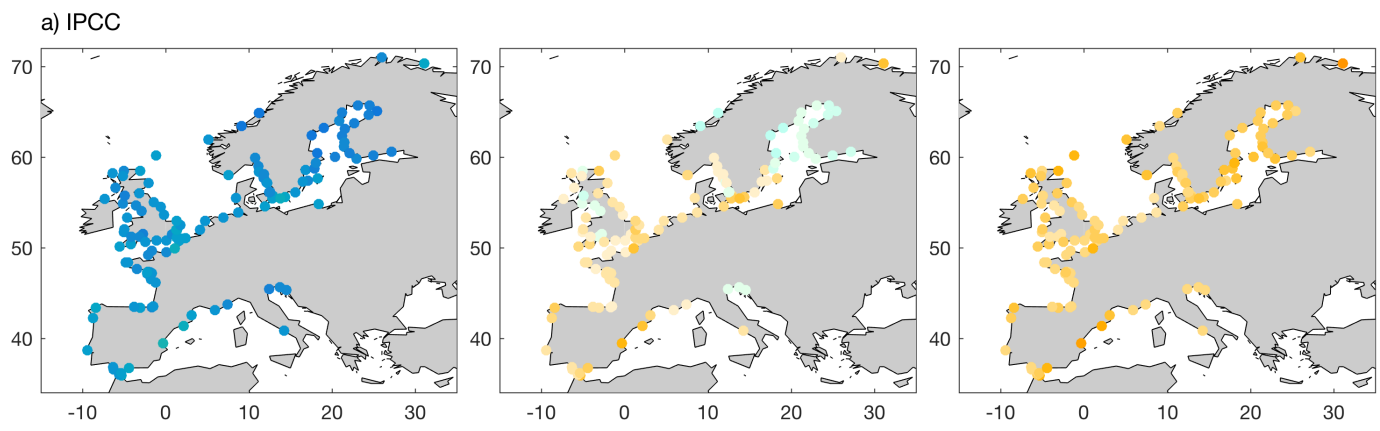

b) VW15 (Greenland and Antarctica dynamics shifted to match IPCC median)

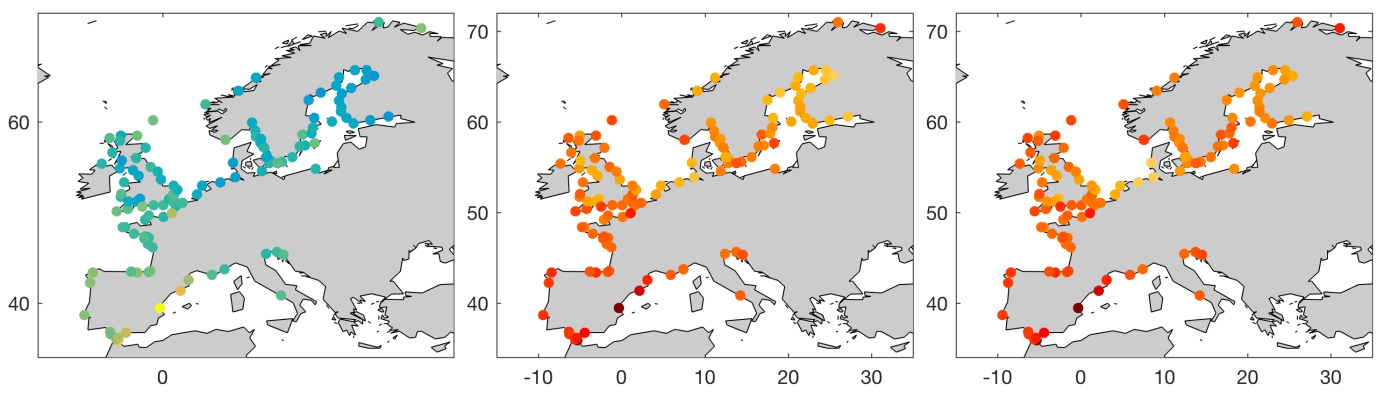

c) R15 (Antarctica dynamics shifted to match IPCC median, Greenland Dynamics = IPCC)


Figure 7. Same as Figure 6, but zoom on European region. Scenarios (a) IPCC; (b) VW15; (c) R15. 

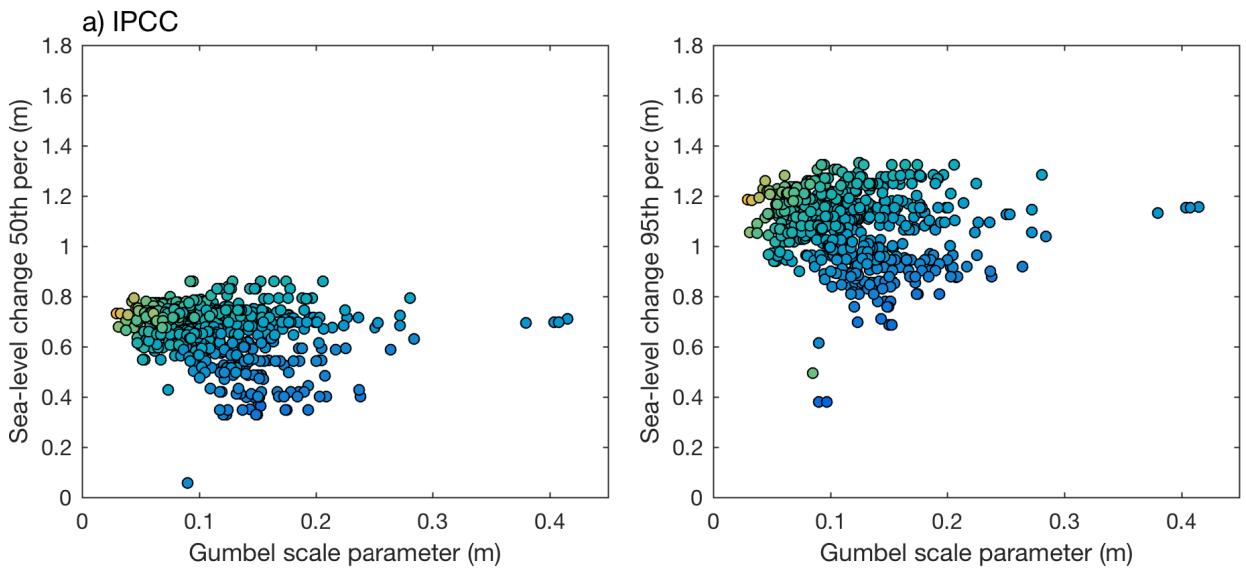

b) VW15 (Greenland and Antarctica Dynamics shifted to match IPCC median)
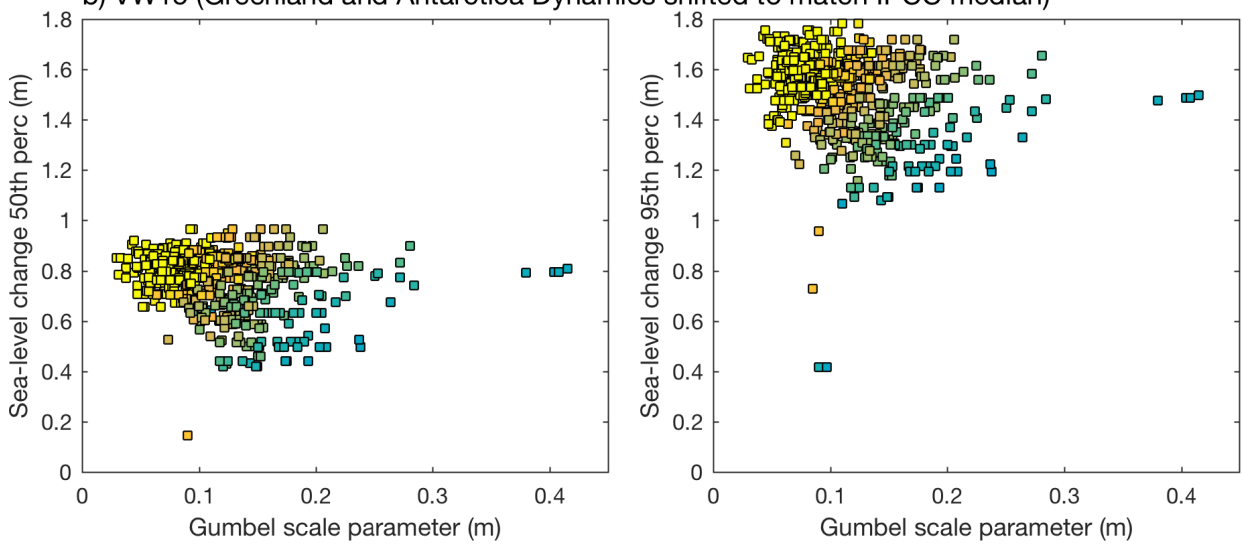

2

c) R15 (Antarctica dynamics shifted to match IPCC median, Greenland Dynamics = IPCC)


Figure 8. Scatter of 2010-2100 change in sea level (m) median (left column) and 95th percentile (right column) vs. the Gumbel scale parameter (m), colourscale indicating allowance (m), for the three scenarios (a) IPCC; (b) VW15; (c) R15. 


\subsection{Changes in the Frequency of Extreme Events}

The frequency of sea-level extremes at any given location will change when mean sea level changes. Looking at Figure 2, the same amount of SLR would have a larger effect on the number of extreme events in places with small variability (both in sense of total range of variability and in the small variability in the extremes, such as Barcelona and Gan, Figure 2a,c). In these places, even $0.5 \mathrm{~m}$ of SLR would bring the mean sea level outside the range of current sea-level variability. In places such as Delfzijl and Willapa Bay (Figure 2b,d), which have a larger range already, a mean SLR of $0.5 \mathrm{~m}$ would not be out of the ordinary range of variability. However, it would mean that the extremes, which are already of considerable magnitude, would become even larger.

The sea-level allowance (Equation (6)) is designed such that a location maintains the same frequency of extremes when the infrastructure is raised by the amount of the allowance. To quantify the effect of not applying the allowance (i.e., the infrastructure is not moved), we compute the change in the frequency of extremes $N$ following

$$
N=\exp (a / \lambda)
$$

where $a$ is the (skewed or normal) allowance and $\lambda$ the Gumbel scale parameter. If the frequency of the extremes increases by a factor 500 this means that a 1 in 10,000 year extreme event will by 2100 occur once every 20 years. For a factor 5, the 1 in 10,000 year event would become a 1 in 2000 year event. It is therefore important to consider regional sea-level projections and their uncertainties, and sea-level extreme statistics, which all differ significantly between different locations.

The changing frequencies of extreme events for the IPCC and R15 scenarios (Figure 9), computed using Equation (7), show larger increases than in (Church et al. [1] their Figure 13.25), due to the use of the RCP8.5 scenario here rather than the RCP4.5 scenario in Figure 13.25b. Another difference with respect to Church et al. [1] is that there are more stations with updated time series included in Figure 9, which can lead to small variations in the Gumbel scale parameter $\lambda$. Since the allowances for the VW15 scenario are on average twice as large as the allowances in the other two scenarios due to the skewed uncertainty distribution, the increase in frequencies is even larger due to the exponent in Equation (7) (Figure 9, Table 1). Overall, the largest increases in frequencies are projected in the Equatorial Pacific and along the Southern and Eastern coasts of the U.S., where projected SLR and uncertainties are relatively large and Gumbel scale parameters are small. If Equation (7) results in ratios of more than $10^{4}$, this means that a 1 in 10,000 year event would occur at least once every year by 2100, and a 1 in 100 year event would occur at least 100 times per year by 2100 . Factors over $10^{4}$ therefore effectively mean that a coastal structure, designed for any normal range of return periods (i.e., 100-10,000 years), would be lost unless the allowance is applied. For IPCC and R15, we find factors over $10^{4}$ for $50 \%$ and $52 \%$ of the tide gauge locations, respectively, while, for VW15, this increases to $87 \%$ due to the skewed ice sheet contribution (Table 1).

Table 1. Percentage (number) of tide gauge stations for every $10^{n}$ increase in the frequency of extreme events by 2100 per ice sheet scenario IPCC, VW15 and R15).

\begin{tabular}{cccc}
\hline $\mathbf{1 0}^{n}$ & IPCC & VW15 & R15 \\
\hline $0-1$ & $1 \%(6)$ & $0 \%(2)$ & $1 \%(6)$ \\
$1-2$ & $11 \%(73)$ & $1 \%(9)$ & $10 \%(67)$ \\
$2-3$ & $21 \%(139)$ & $6 \%(37)$ & $21 \%(136)$ \\
$3-4$ & $17 \%(109)$ & $6 \%(39)$ & $16 \%(105)$ \\
$>4$ & $50 \%(325)$ & $87 \%(565)$ & $52 \%(338)$ \\
\hline
\end{tabular}



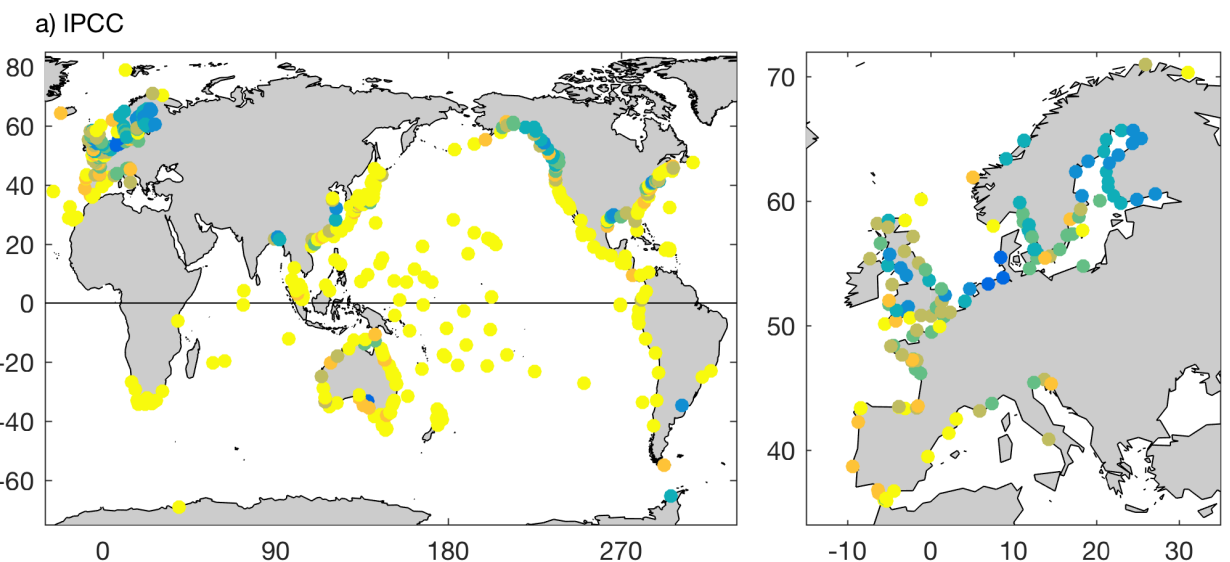

b) VW15 (Greenland and Antarctica dynamics shifted to match IPCC median)
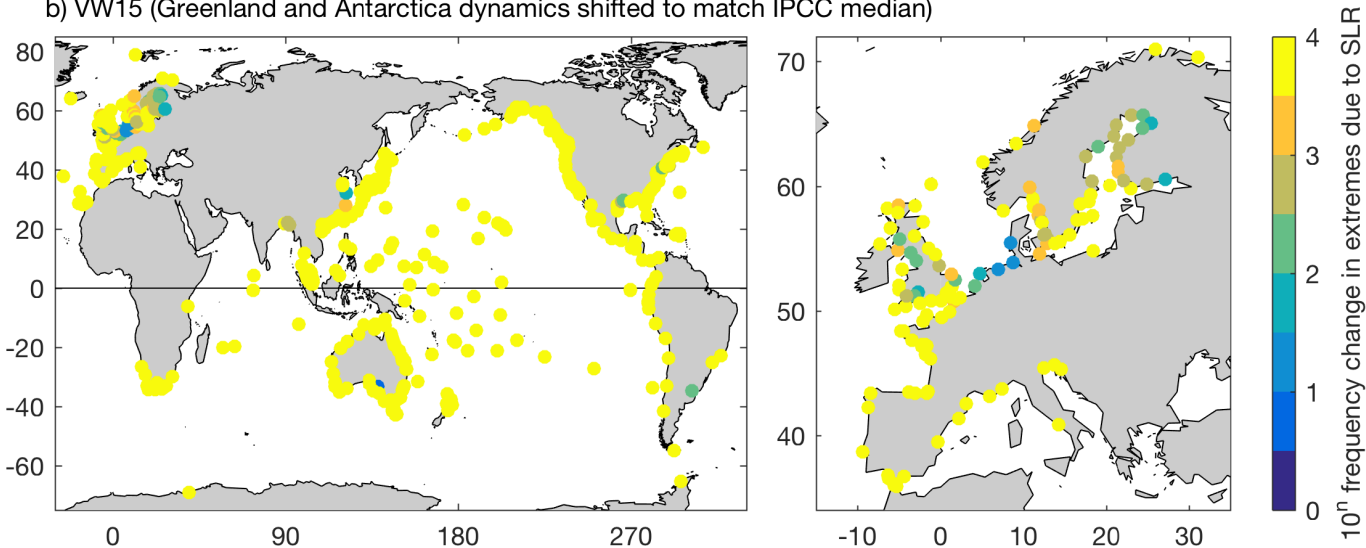

c) R15 (Antarctica dynamics shifted to match IPCC median, Greenland dynamics = IPCC)
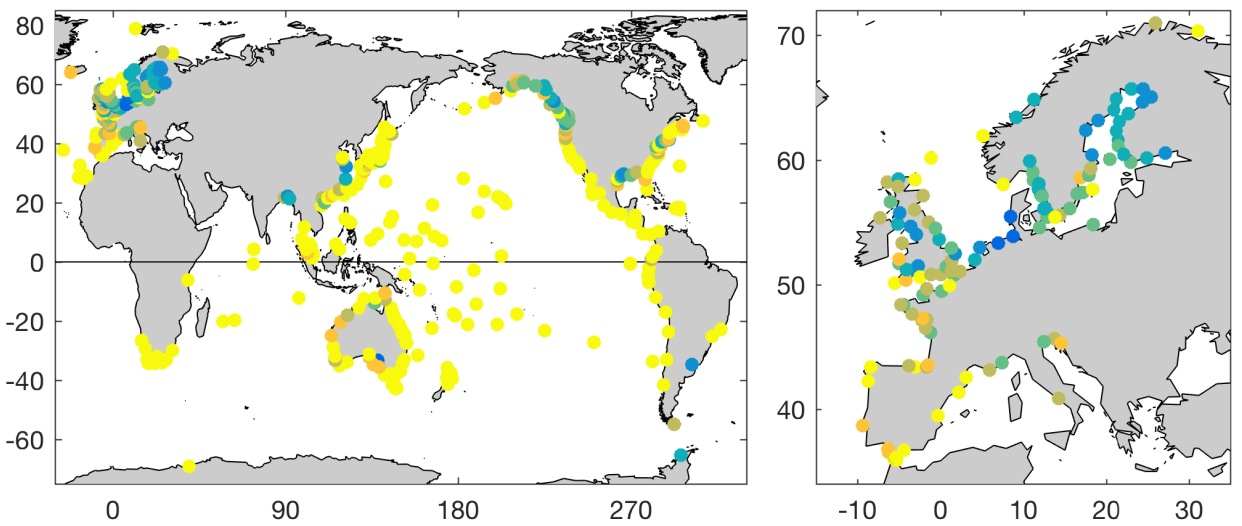

Figure 9. Ratio of the change in the frequency of extreme events (2100 vs. 2010) if allowances are not applied, based on the (a) IPCC (b) VW15 and (c) R15 sea-level change scenario. Note the logarithmic scale. A limit of $10^{4}$ has been imposed, as frequency increases above this level mean that a coastal structure effectively would be lost if no allowance is applied.

\section{Discussion}

In computing the allowances, several choices and assumptions were made for the projected mean SLR and for the representation of extreme sea levels.

Regarding the projections, we used the RCP8.5 scenario as presented in Slangen et al. [12]. The RCP8.5 scenario is chosen because it is currently the more realistic option among the available scenarios, which is therefore relevant for coastal protection. Compared to the projections presented in [1], there are small differences (for the period 1986-2005 vs. 2080-2100, RCP8.5 scenario) in the individual contributions: glaciers $(+6 \mathrm{~cm})$, Greenland SMB $(-1 \mathrm{~cm})$, Antarctic SMB $(-4 \mathrm{~cm})$, Greenland 
Dynamics $(+1 \mathrm{~cm})$, Antarctic Dynamics $(+2 \mathrm{~cm})$ and groundwater depletion $(+4 \mathrm{~cm})$. The main reason is that Slangen et al. [12] used one model or approach for each contribution to sea level, while the IPCC AR5 projections are based on an assessment of multiple estimates for each contribution. As a result, the global mean SLR under the RCP8.5 scenario is $71 \mathrm{~cm}$ in Slangen et al. [12], compared to $63 \mathrm{~cm}$ in IPCC AR5 (for 2081-2100 relative to 1986-2005). However, the methodology used for computing regional patterns is the same for the IPCC AR5 and the Slangen et al. [12] projections, and therefore any differences are mainly in the magnitude of the signal rather than the spatial distribution.

For the contributions of the ice sheet dynamics, we used three different shapes for the uncertainty distributions, from three different sources. The IPCC estimate is a consensus estimate, based on a multitude of models and publications, the VW15 estimate is based on an expert elicitation, and the R15 estimate is based on physical and statistical models. We chose to use these published estimates of the actual ice sheet dynamical contributions rather than completely artificial uncertainty distributions, which probably would have not included a distribution with the shape of the R15 distribution. A systematic sensitivity study could be part of future work. Nevertheless, the current set of distributions shows that a highly skewed distribution leads to much higher estimates of the allowances. It is therefore very important to better understand the shape of the uncertainty distribution using physical understanding and modelling, as the uncertainties are critical to estimating future SLR and to decide on the necessary coastal protection.

In order to focus on the influence of the shape of the uncertainty distributions rather than the actual magnitude, we shifted all distributions such that they matched the median values of IPCC. If we compare the differences in allowances before and after the shift of the medians, we find that for the VW15 scenario the shift in the median SLR projections is $-12 \mathrm{~cm}$, but the impact on the allowances (comparing allowances with and without median shift) is $-8 \mathrm{~cm}$. For the R15 scenarios, the medians were shifted by only $-3 \mathrm{~cm}$, and the impact on the allowances is $-4 \mathrm{~cm}$.

With regard to the use of the Gumbel scale parameter, which is based on annual maximum sea levels, it is considered to be a method that is relatively straightforward, but perhaps not the ideal representation of sea-level extremes. It is relatively robust for temporal and spatial variations and therefore widely used for global applications [32], but, on the other hand, does not use all the information that is available. Some other potential methods, such as the Generalised Extreme Value distribution or a Generalised Pareto distribution, include more information, as they not only provide a slope, but also a shape of the extreme value distribution [33]. However, these more complicated distributions cannot (yet) be used to compute allowances. In a potential follow-up of this work, it would be useful to examine the effect of different types of extreme value distributions on sea-level allowances, but here we chose to focus on the sensitivity to the shape of the sea-level projection uncertainties alone.

Generally, the longer the time period used, the better the estimate of the extreme sea-level variability [34]. Here, we use a minimum of 20 years of data in the tide gauge record as a constraint, but find that the average allowance only varies with a maximum of $0.06 \mathrm{~m}$ for the VW15 scenario when selecting longer time series (which results in less tide gauge records): $2.19 \mathrm{~m}$ for $\geq 20$ years vs. 2.13 for records $\geq 50$ years. For IPCC and R15, the differences are even smaller and the selection of longer time series has a negligible effect on the allowances (respectively, 1.01 and $1.03 \mathrm{~m}$ for $\geq 20$ years and, respectively, 1.00 and $1.02 \mathrm{~m}$ for $\geq 50$ years). One caveat for all extreme value statistics is that they depend on the occurrence of extreme events in the observational period, which becomes a more relevant restriction for longer return periods (e.g., 1 in 10,000 years) [35]. As a result, the statistics may change significantly when new extreme events are included in the analysis and it is therefore important to keep them up to date.

A final assumption regarding the statistics of the extremes is that they do not change over time, i.e., that both the magnitude with respect to the mean sea level and the frequency not change. This assumption is supported by observations and analysis of past extreme sea levels, which show that the observed changes in the frequency of flooding events is mainly caused by the increase in mean 
sea levels (e.g., [11]). However, the statistics of storms, and therefore of sea-level extremes, could well change significantly in the future. It is important to keep in mind that sea level can also rise due to local land subsidence, for instance due to groundwater extraction. In some locations, the subsidence even exceeds the climate-driven sea-level rise and therefore amplifies the flooding frequency [36] and changes the location of the coastline due to submergence of the coast. However, information on vertical land motion (VLM, measured with GPS) is not available all over the world and projections are difficult since they directly depend on human decisions. Therefore, VLM and changing coastlines could not yet be taken into account in the sea-level projections.

\section{Conclusions}

We have compared and contrasted three different scenarios for the projected dynamical ice sheet contribution to SLR. For each scenario, we combined information on sea-level extremes at more than 650 tide gauge stations with regional SLR projections in 2100 with respect to 2010, to compute so-called sea-level allowances. An allowance is a guide for the expected height a coastal structure needs to be elevated to keep the same flooding frequency. Allowances depend not only on the mean SLR, but also on the uncertainty in the mean sea-level projection and on the variability and magnitude of sea-level extremes. Each of the three sea-level projection scenarios has a different shape for the uncertainty distributions in the ice sheet dynamics contributions, leading to differences in the allowances.

We found that the allowances change significantly for our skewed scenario, doubling their values compared to allowances based on a normal distribution of the ice sheet dynamics. This is due to a heavier upper tail associated with higher contributions from ice sheet dynamics (the low-probability/high-impact events). The IPCC-based 95\% SLR at the tide gauge stations is $1.08 \mathrm{~m}$, with an average allowance of $1.01 \mathrm{~m}$, while the skewed VW15 scenario leads to a projected $95 \%$ SLR of $1.50 \mathrm{~m}$ at the tide gauges and a much larger allowance of $2.19 \mathrm{~m}$. For the R15 scenario, which has a less skewed but still non-normal distribution, the 95\% SLR at the tide gauges is $1.12 \mathrm{~m}$ and the average allowance is $1.03 \mathrm{~m}$. This sensitivity to the skewness of the uncertainty distribution means that it is very important to improve estimates of ice sheet dynamics contributions to SLR, and in particular their uncertainties. As we focused on the shape of the uncertainty distribution here rather than the magnitude, computations of allowances should be repeated with improved ice sheet uncertainty distributions to deliver allowances that are suitable for decision making and coastal protection.

The sea-level allowances are largest in regions with a relatively small variability in sea-level extremes and SLR projections of large magnitude and/or uncertainty. These are also the regions where frequencies in extremes will increase most if the allowances are not applied (i.e., coastal structure is not elevated), especially for the skewed probabilities in the VW15 scenario. Most of these vulnerable locations are in the tropics, where the largest regional sea-level changes (and uncertainties) are projected due to increasing thermal expansion and above-average regional contributions due to land ice mass loss [12]. This means that these regions would also be particularly vulnerable to larger contributions from the ice sheets.

Here, the computation of allowances could only be done at tide gauge locations, as this is where high-resolution observational time series are available for reasonable lengths of time. It would, however, be interesting to try and fill in the gaps for the entire coastline, using modelling approaches. Recently, Muis et al. [32] published a global set of extreme sea levels and storm surges (the GTSR data set), including Gumbel scale parameters along the global coastline, which showed good agreement between observations and the model data set. This set could possibly be used in future work to provide sea-level allowances at all coastal locations, which would be helpful for coastal planning purposes. 
Acknowledgments: We gratefully acknowledge the contributors to the GESLA-2 database which are listed on www.gesla.org. A.B.A.S. and R.C.d.W. were funded by the NWO Netherlands Polar Programme, and T.J.R. was funded by the Netherlands Earth Science Center. P.L.W. was funded partly by the Leverhulme Trust.

Author Contributions: A.B.A.S. and R.S.W.v.d.W. conceived and designed the experiments; A.B.A.S. performed the experiments, analysed the data and wrote the paper; and all authors contributed to the writing of the paper. R.S.W.v.d.W., R.C.d.W. and T.J.R. designed the SEAWISE model and T.J.R. developed the code. J.R.H., P.L.W. and T.E. contributed with data and analysis tools.

Conflicts of Interest: The authors declare no conflict of interest.

\section{Abbreviations}

The following abbreviations are used in this manuscript:

$\begin{array}{ll}\text { AR5 } & \text { Fifth Assessment Report } \\ \text { CMIP5 } & \text { 5th phase of the Climate Model Intercomparison Project } \\ \text { EAIS } & \text { East Antarctic Ice Sheet } \\ \text { GESLA-2 } & \text { Global Extreme Sea Level Analysis Version } 2 \\ \text { GRIS } & \text { Greenland Ice Sheet } \\ \text { IPCC } & \text { Intergovernmental Panel on Climate Change } \\ \text { RCP } & \text { Representative Concentration Pathway } \\ \text { SLR } & \text { Sea-Level Rise } \\ \text { WAIS } & \text { West Antarctic Ice Sheet }\end{array}$

\section{Appendix A. SEAWISE Methodology}

SEAWISE is used to combine different uncertainty distributions, e.g., Greenland $\left(P_{1}\right)$ and West-Antarctica $\left(P_{2}\right)$, into one uncertainty distribution (e.g., $\left.P_{\text {combined } 1}\right)$. The composed distribution $P_{\text {combined } 1}(z)$ (where $z$ is the projected SLR) exists for each $z$ of all contributions of two independent distributions $P_{1}\left(z_{1}\right)$ and $P_{2}\left(z_{2}\right)$ for which the summed values $z_{1}$ and $z_{2}$ add to $z$. $P_{\text {combined } 1}(z)$ is the resulting combined uncertainty distribution of $P_{1}\left(z_{1}\right)$ and $P_{2}\left(z_{2}\right)$ :

$$
P_{\text {combined } 1}(z)=\sum_{m=c}^{d} P_{1}(z-m \Delta z) P_{2}(m \Delta z)
$$

All data within $6 \sigma$-boundaries around the mode of each distribution is selected, which usually covers over $99.9 \%$ of the data. The distribution is normalized based on this selected part. In Equation (A1), the interval counter $m$ runs in steps of $\Delta z$ between $c$ and $d$ corresponding with $z_{c}$ and $z_{d}$, respectively the left and right $6 \sigma$-boundaries of $P_{2}$, while taking $z_{1}=z-m \Delta z$ and $z_{2}=m \Delta z$. To obtain the entire distribution $P_{\text {combined } 1}(z)$, Equation (A1) is calculated for all $z$ between $z_{a}$ at the left $6 \sigma$-boundary of $P_{1}$ and $z_{b}+z_{d}$, where $z_{b}$ is the right $6 \sigma$-boundary of $P_{1}$ and $z_{d}$ the right $6 \sigma$-boundary of $P_{2}$. In this way, the uncertainty distribution for each SLR contribution can be added, until all uncertainty distributions are combined (Figure A1). In addition to providing the combined uncertainty distributions for single points, SEAWISE can produce global maps of the SLR mode, SLR median and a number of SLR $n$th percentiles or SLR $n$th $\sigma$-intervals [18]. 

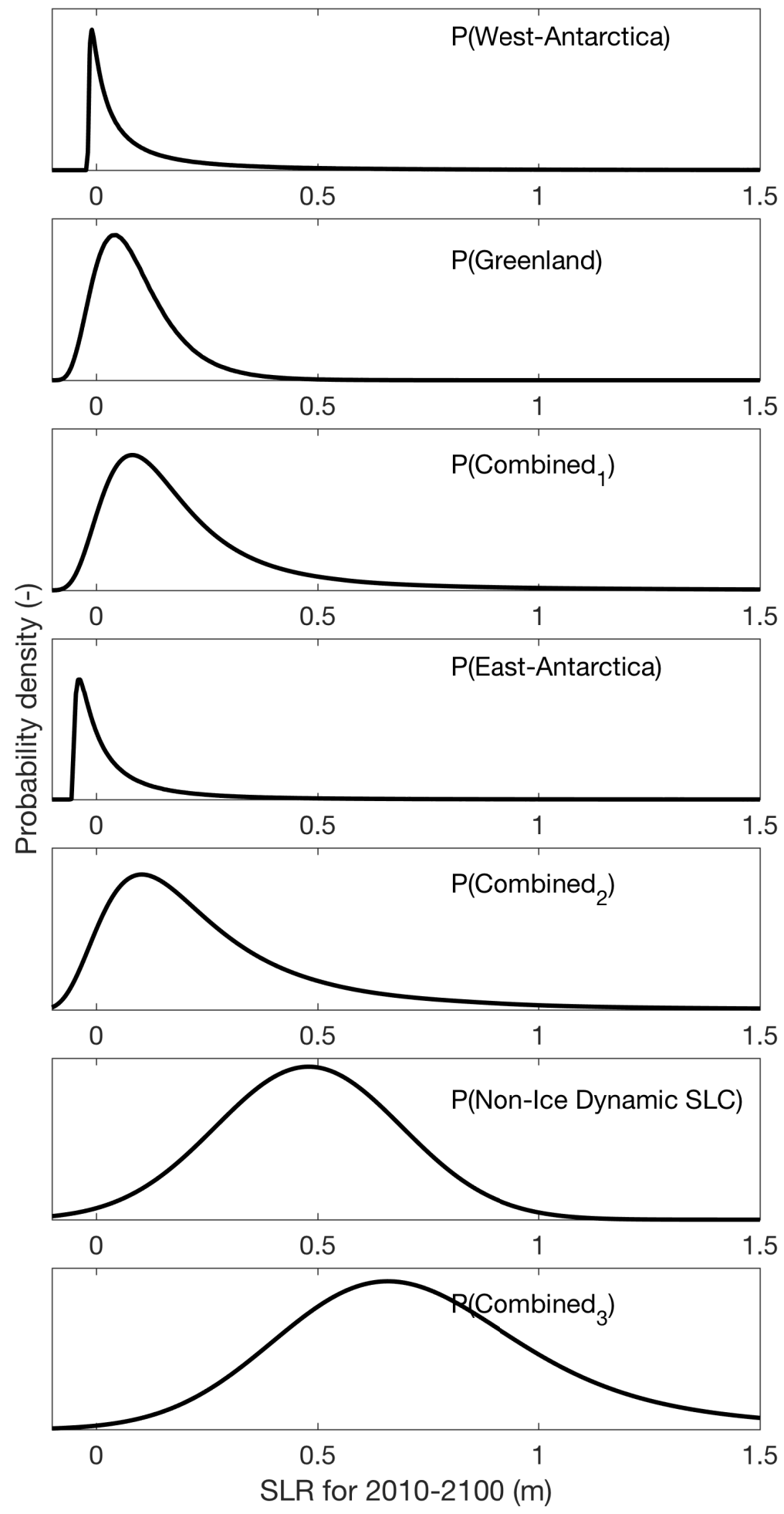

Figure A1. An example showing the SEAWISE methodology which step-wise combines different

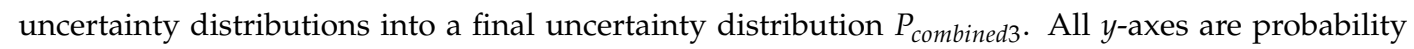
density (dimensionless). This example is for a grid point off the Canadian coast (290W-67N), using the VW15 scenario for the ice sheet dynamics contributions. P(Non-Ice Dynamic SLR) contains the contributions from glaciers, ocean density variations and ocean dynamics, ice sheet surface mass balance, groundwater extraction and glacial isostatic adjustment [12]. 


\section{References}

1. Church, J.; Clark, P.; Cazenave, A.; Gregory, J.; Jevrejeva, S.; Levermann, A.; Merrifield, M.; Milne, G.; Nerem, R.; Nunn, P.; et al. Sea Level Change. In Climate Change 2013: The Physical Science Basis. Contribution of Working Group I to the Fifth Assessment Report of the Intergovernmental Panel on Climate Change; Stocker, T., Qin, D., Plattner, G.K., Tignor, M., Allen, S., Boschung, J., Nauels, A., Xia, Y., Bex, V., Midgley, P., Eds.; Cambridge University Press: Cambridge, UK; New York, NY, USA, 2013.

2. Clark, P.U.; Church, J.A.; Gregory, J.M.; Payne, A.J. Recent Progress in Understanding and Projecting Regional and Global Mean Sea Level Change. Curr. Clim. Chang. Rep. 2015, 1, 224-246.

3. Slangen, A.B.A.; Adloff, F.; Jevrejeva, S.; Leclercq, P.W.; Marzeion, B.; Wada, Y.; Winkelmann, R. A Review of Recent Updates of Sea-Level Projections at Global and Regional Scales. Surv. Geophys. 2016, 38, 385-406.

4. Bamber, J.L.; Aspinall, W.P. An expert judgement assessment of future sea level rise from the ice sheets. Nat. Clim. Chang. 2013, 3, 424-427.

5. De Vries, H.; van de Wal, R.S.W. How to interpret expert judgment assessments of 21st century sea-level rise. Clim. Chang. 2015, 130, 87-100.

6. Favier, L.; Durand, G.; Cornford, S.L.; Gudmundsson, G.H.; Gagliardini, O.; Gillet-Chaulet, F.; Zwinger, T.; Payne, A.J.; le Brocq, A.M. Retreat of Pine Island Glacier controlled by marine ice-sheet instability. Nat. Clim. Chang. 2014, 4, 117-121.

7. Joughin, I.; Smith, B.E.; Medley, B. Marine Ice Sheet Collapse Potentially Under Way for the Thwaites Glacier Basin, West Antarctica. Science 2014, 344, 735-738.

8. Ritz, C.; Edwards, T.L.; Durand, G.; Payne, A.J.; Peyaud, V.; Hindmarsh, R.C.A. Potential sea-level rise from Antarctic ice-sheet instability constrained by observations. Nature 2015, 528, 115-118.

9. Hunter, J. A simple technique for estimating an allowance for uncertain sea-level rise. Clim. Chang. 2012, 113, 239-252.

10. Hunter, J.R.; Church, J.A.; White, N.J.; Zhang, X. Towards a global regionally varying allowance for sea-level rise. Ocean Eng. 2013, 71, 17-27.

11. Menéndez, M.; Woodworth, P.L. Changes in extreme high water levels based on a quasi-global tide-gauge dataset. J. Geophys. Res. 2010, 115, C10011.

12. Slangen, A.B.A.; Carson, M.; Katsman, C.; van de Wal, R.; Koehl, A.; Vermeersen, L.; Stammer, D. Projecting twenty-first century regional sea-level changes. Clim. Chang. 2014, 124, 317-332.

13. Moss, R.H.; Edmonds, J.A.; Hibbard, K.A.; Manning, M.R.; Rose, S.K.; van Vuuren, D.P.; Carter, T.R.; Emori, S.; Kainuma, M.; Kram, T.; et al. The next generation of scenarios for climate change research and assessment. Nature 2010, 463, 747-756.

14. Taylor, K.; Stouffer, R.J.; Meehl, G.A. An overview of CMIP5 and the experiment design. Bull. Am. Meteorol. Soc. 2012, 93, 485-498.

15. Kopp, R.E.; Horton, R.M.; Little, C.M.; Mitrovica, J.X.; Oppenheimer, M.; Rasmussen, D.J.; Strauss, B.H.; Tebaldi, C. Probabilistic 21st and 22nd century sea-level projections at a global network of tide-gauge sites. Earth Future 2014, 2, 383-406.

16. Jackson, L.P.; Jevrejeva, S. A probabilistic approach to 21st century regional sea-level projections using RCP and High-end scenarios. Glob. Planet. Chang. 2016, 146, 179-189.

17. Jevrejeva, S.; Jackson, L.P.; Riva, R.E.M.; Grinsted, A.; Moore, J.C. Coastal sea level rise with warming above $2{ }^{\circ}$ C. Proc. Natl. Acad. Sci. USA 2016, 113, 13342-13347.

18. De Winter, R.; Reerink, T.J.; de Vries, H.; Slangen, A.B.A.; van de Wal, R.S.W. Impact of asymmetric uncertainties in ice sheet dynamics on regional sea level projections. Nat. Hazards Earth Syst. Sci. Discuss. 2017, In Review.

19. Buchanan, M.K.; Kopp, R.E.; Oppenheimer, M.; Tebaldi, C. Allowances for evolving coastal flood risk under uncertain local sea-level rise. Clim. Chang. 2016, 137, 347-362.

20. Coles, S. An Introduction to Statistical Modeling of Extreme Values; Springer: London, UK, 2001.

21. Arns, A.; Wahl, T.; Haigh, I.D.; Jensen, J.; Pattiaratchi, C. Estimating extreme water level probabilities: A comparison of the direct methods and recommendations for best practise. Coast. Eng. 2013, 81, 51-66.

22. GESLA. Available online: www.gesla.org (accessed on 23 May 2017).

23. Woodworth, P.; Hunter, J.; Marcos, M.; Caldwell, P.; Menendez, M.; Haigh, I. Towards a global higher-frequency sea level data set. Geosci. Data J. 2016, 3, 50-59. 
24. Shepherd, A.; Ivins, E.R.; Geruo, A.; Barletta, V.R.; Bentley, M.J.; Bettadpur, S.; Briggs, K.H.; Bromwich, D.H.; Forsberg, R.; Galin, N.; et al. A Reconciled Estimate of Ice-Sheet Mass Balance. Science 2012, 338, 1183-1189.

25. Mitrovica, J.X.; Tamisiea, M.E.; Davis, J.L.; Milne, G.A. Recent mass balance of polar ice sheets inferred from patterns of global sea-level change. Nature 2001, 409, 1026-1029.

26. Hunter, J.R.; Woodworth, P.L.; Wahl, T.; Nicholls, R.J. Using Global Tide Gauge Data to Validate and Improve the Representation of Extreme Sea Levels in Flood Impact Studies. Glob. Planet. Chang. 2017, Under Review.

27. Merrifield, M.A.; Genz, A.S.; Kontoes, C.P.; Marra, J.J. Annual maximum water levels from tide gauges: Contributing factors and geographic patterns. J. Geophys. Res. Oceans 2013, 118, 2535-2546.

28. De Winter, R.C.; Sterl, A.; Ruessink, B.G. Wind extremes in the North Sea Basin under climate change: An ensemble study of 12 CMIP5 GCMs. J. Geophys. Res. Atmos. 2013, 118, 1601-1612.

29. Press, W.; Teukolsky, S.A.; Vetterling, W.T.; Flannery, B.P. Numerical Recipes 3rd Edition: The Art of Scientific Computing, 3rd ed.; Cambridge University Press: New York, NY, USA, 2007.

30. Slangen, A.B.A.; Church, J.A.; Zhang, X.; Monselesan, D. The sea-level response to external forcings in CMIP5 climate models. J. Clim. 2015, 28, 8521-8539.

31. Tamisiea, M.E.; Mitrovica, J.X. The moving boundaries of sea level change: Understanding the origins of geographic variability. Oceanography 2011, 24, 24-39.

32. Muis, S.; Verlaan, M.; Winsemius, H.C.; Aers, J.C.J.H.; Ward, P.J. A global reanalysis of storm surges and extreme sea levels. Nat. Commun. 2016, 7, 11969.

33. Wahl, T.; Haigh, I.; Nicholls, R.; Arns, A.; Dangendorf, S.; Hinkel, J.; Slangen, A. Understanding extreme sea levels for broad-scale coastal impact and adaptation analysis. Nat. Commun. 2017, Accepted.

34. Haigh, I.D.; Nicholls, R.; Wells, N. A comparison of the main methods for estimating probabilities of extreme still water levels. Coast. Eng. 2010, 57, 838-849.

35. Dangendorf, S.; Arns, A.; Pinto, J.G.; Ludwig, P.; Jensen, J. The exceptional influence of storm 'Xaver' on design water levels in the German Bight. Environ. Res. Lett. 2016, 11, 045001.

36. Erkens, G.; Bucx, T.; Dam, R.; de Lange, G.; Lambert, J.L. Sinking coastal cities. Proc. IAHS 2015, 372, 189-198.

(C) 2017 by the authors. Licensee MDPI, Basel, Switzerland. This article is an open access article distributed under the terms and conditions of the Creative Commons Attribution (CC BY) license (http:// creativecommons.org/licenses/by/4.0/). 